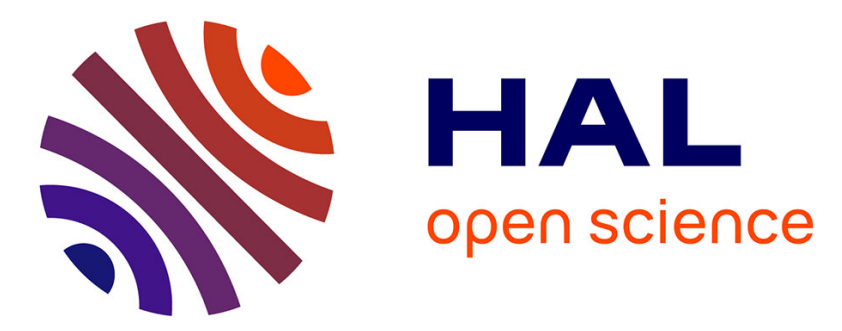

\title{
Effects of interspecific coexistence on laying date and clutch size in two closely related species of hole-nesting birds
}

Anders Pape Møller, Javier Balbontin, André Dhondt, Vladimir Remeš, Frank Adriaensen, Clotilde Biard, Jordi Camprodon, Mariusz Cichoń, Blandine Doligez, Anna Dubiec, et al.

\section{To cite this version:}

Anders Pape Møller, Javier Balbontin, André Dhondt, Vladimir Remeš, Frank Adriaensen, et al.. Effects of interspecific coexistence on laying date and clutch size in two closely related species of holenesting birds. Journal of Animal Ecology, 2018, 87 (6), pp.1738-1748. 10.1111/1365-2656.12896 . hal-02413051

\section{HAL Id: hal-02413051 \\ https://cnrs.hal.science/hal-02413051}

Submitted on 20 Nov 2020

HAL is a multi-disciplinary open access archive for the deposit and dissemination of scientific research documents, whether they are published or not. The documents may come from teaching and research institutions in France or abroad, or from public or private research centers.
L'archive ouverte pluridisciplinaire HAL, est destinée au dépôt et à la diffusion de documents scientifiques de niveau recherche, publiés ou non, émanant des établissements d'enseignement et de recherche français ou étrangers, des laboratoires publics ou privés. 


\title{
Effects of interspecific coexistence on laying date and clutch size in two closely related species of hole-nesting birds
}

\author{
Anders Pape Møller ${ }^{1}$ (D) | Javier Balbontín ${ }^{2}$ | André A. Dhondt ${ }^{3}$ | Vladimir Remeš ${ }^{4}$ | \\ Frank Adriaensen $^{5}$ | Clotilde Biard $^{6}$ | Jordi Camprodon ${ }^{7}$ | Mariusz Cichoń ${ }^{8}$ | \\ Blandine Doligez $^{9}$ | Anna Dubiec ${ }^{10}$ | Marcel Eens ${ }^{11}$ | Tapio Eeva ${ }^{12}$ | \\ Anne E. Goodenough ${ }^{13}$ | Andrew G. Gosler ${ }^{14}$ | Lars Gustafsson ${ }^{15}$ | \\ Philipp Heeb $^{16}$ | Shelley A. Hinsley ${ }^{17}$ | Staffan Jacob ${ }^{18}$ | Rimvydas Juškaitis ${ }^{19}$ \\ Toni Laaksonen $^{20}$ | Bernard Leclercq ${ }^{21}$ | Bruno Massa ${ }^{22}$ | Tomasz D. Mazgajski ${ }^{10}$ | \\ Ruedi G. Nager $^{23}$ | Jan-Åke Nilsson ${ }^{24}$ | Sven G. Nilsson ${ }^{25}$ | Ana C. Norte ${ }^{26}$ | \\ Rianne Pinxten ${ }^{11,27}$ | Hugo Robles ${ }^{28,29}$ | Tapio Solonen ${ }^{30}$ | Alberto Sorace ${ }^{31}$ | \\ Arie J. van Noordwijk ${ }^{32}$ | Marcel M. Lambrechts ${ }^{33}$
}

${ }^{1}$ Ecologie Systematique Evolution, CNRS, AgroParisTech, Université Paris-Saclay, Orsay Cedex, France; ${ }^{2}$ Departamento de Zoología, Facultad de Biología, Universidad de Sevilla, Sevilla, Spain; ${ }^{3}$ Laboratory of Ornithology, Cornell University, Ithaca, NY, USA; ${ }^{4}$ Laboratory of Ornithology, Department of Zoology, Palacky University, Olomouc, Czech Republic; ${ }^{5}$ Evolutionary Ecology Group, Department of Biology, University of Antwerp, Antwerp, Belgium; ${ }^{6}$ IEESParis - Institut d'Ecologie et des Sciences de l'Environnement, Sorbonne Universités, UPMC Univ Paris 06, UPEC, Paris, France; ${ }^{7}$ Àrea de Biodiversitat, Grup de Biologia de la Conservació, Centre Tecnològic Forestal de Catalunya, Solsona, Spain; ${ }^{8}$ Institute of Environmental Sciences, Jagiellonian University, Krakow, Poland; ${ }^{9} \mathrm{CNRS}$, Laboratoire de Biométrie et Biologie Evolutive, UMR 5558, Université Lyon 1, Université de Lyon, Villeurbanne Cedex, France; ${ }^{10}$ Museum and Institute of Zoology, Polish Academy of Sciences, Warsaw, Poland; ${ }^{11}$ Department of Biology, Behavioural Ecology \& Ecophysiology Group, Campus Drie Eiken, Antwerp, Belgium; ${ }^{12}$ Department of Biology, University of Turku, Turku, Finland; ${ }^{13}$ Department of Natural and Social Sciences, University of Gloucestershire, Cheltenham, UK; ${ }^{14}$ Department of Zoology, Edward Grey Institute of Field Ornithology \& Institute of Human Sciences, Oxford, UK; ${ }^{15}$ Department of Animal Ecology, Evolutionary Biolpgy Centre, Uppsala University, Uppsala, Sweden; ${ }^{16}$ Laboratoire Évolution \& Diversité Biologique, UPS Toulouse III, Toulouse, France; ${ }^{17} \mathrm{CEH}$ Wallingford, Wallingford, UK; ${ }^{18}$ Station d'Ecologie Expérimentale du CNRS à Moulis, USR CNRS 2936, Moulis, France; ${ }^{19}$ Institute of Ecology of Nature Research Centre, Vilnius, Lithuania; ${ }^{20}$ Section of Ecology, Department of Biology, University of Turku, Turku, Finland; ${ }^{21}$ Fleurey-sur-Ouche, France; ${ }^{22}$ Department of Agricultural, Food and Forest Sciences, Università di Palermo, Palermo, Italy; ${ }^{23}$ Institute of Biodiversity, Animal Health \& Comparative Medicine, University of Glasgow, Glasgow, UK; ${ }^{24}$ Department of Biology, Evolutionary Ecology, Lund University, Lund, Sweden; ${ }^{25}$ Department of Biology, Biodiversity, Lund University, Lund, Sweden; ${ }^{26}$ Department of Life Sciences, Faculty of Sciences and Technology, MARE - Marine and Environmental Sciences Centre, University of Coimbra, Coimbra, Portugal; ${ }^{27}$ Faculty of Social Sciences, Didactica Research Group, University of Antwerp, Antwerp, Belgium; ${ }^{28}$ Evolutionary Ecology Group (GIBE), Faculty of Sciences, University of A Coruña, A Coruña, Spain; ${ }^{29}$ Evolutionary Ecology Group (EVECO), Department of Biology, University of Antwerp, Antwerp, Belgium; ${ }^{30}$ Luontotutkimus Solonen Oy, Helsinki, Finland; ${ }^{31}$ ISPRA, Rome, Italy; ${ }^{32}$ Netherlands Institute of Ecology (NIOO-KNAW), Wageningen, The Netherlands and ${ }^{33}$ Centre d'Ecologie Fonctionnelle et Evolutive, CEFE UMR 5175, Montpellier Cedex 5, France

Correspondence Anders Pape Møller

Email: anders.moller@u-psud.fr

Handling Editor: Daniel Ardia

\section{Abstract}

1. Coexistence between great tits Parus major and blue tits Cyanistes caeruleus, but also other hole-nesting taxa, constitutes a classic example of species co-occurrence resulting in potential interference and exploitation competition for food and for breeding and roosting sites. However, the spatial and temporal variations in coexistence and its consequences for competition remain poorly understood.

2. We used an extensive database on reproduction in nest boxes by great and blue tits based on 87 study plots across Europe and Northern Africa during 1957-2012 for a total of 19,075 great tit and 16,729 blue tit clutches to assess correlative 
evidence for a relationship between laying date and clutch size, respectively, and density consistent with effects of intraspecific and interspecific competition.

3. In an initial set of analyses, we statistically controlled for a suite of site-specific variables. We found evidence for an effect of intraspecific competition on blue tit laying date (later laying at higher density) and clutch size (smaller clutch size at higher density), but no evidence of significant effects of intraspecific competition in great tits, nor effects of interspecific competition for either species.

4. To further control for site-specific variation caused by a range of potentially confounding variables, we compared means and variances in laying date and clutch size of great and blue tits among three categories of difference in density between the two species. We exploited the fact that means and variances are generally positively correlated. If interspecific competition occurs, we predicted a reduction in mean and an increase in variance in clutch size in great tit and blue tit when density of heterospecifics is higher than the density of conspecifics, and for intraspecific competition, this reduction would occur when density of conspecifics is higher than the density of heterospecifics. Such comparisons of temporal patterns of means and variances revealed evidence, for both species, consistent with intraspecific competition and to a smaller extent with interspecific competition.

5. These findings suggest that competition associated with reproductive behaviour between blue and great tits is widespread, but also varies across large spatial and temporal scales.

\section{KEYWORDS}

clutch size, density, interspecific competition, intraspecific competition, nest boxes, reaction norm, spatiotemporal variation

\section{1 | INTRODUCTION}

Numerous experimental studies have demonstrated that intraspecific and interspecific competition can reduce population size or decrease reproductive output (e.g., Dhondt, 2012; Gurevitch, Morrow, Wallace, \& Walsh, 1992; Schoener, 1983). Competition, defined as the negative effects that one organism has upon another, may be due to interference over resources and/or to exploitation of resources that are limited in availability (Grover, 1997; Keddy, 1989). The limiting resources over which individuals compete vary considerably, as does the timing of competition during the annual cycle. However, factors other than competition such as compensation can also drive population dynamics (Houlahan et al., 2007; Ricklefs, 2012). Because of such complexity, competition is not inevitable; indeed, a recent study of interspecific competition between two hole-nesting bird species in four European populations showed clear evidence of competition in only three of these populations (Stenseth et al., 2015). Similarly, in a review of density dependence of clutch size in titmice, Both (2000) only found a negative relationship in half of all study plots, again emphasizing that decreased reproduction is not a ubiquitous outcome.

Great tits Parus major and blue tits Cyanistes caeruleus, both secondary hole-nesting passerines, constitute a classic example of competition for food and cavities (review in Dhondt, 2012). For example, Dhondt and Eyckerman (1980a) showed that high density of both species reduced reproductive output in great tits. In contrast to great tits, evidence for effects of both intraspecific and interspecific competition on reproduction is much weaker in blue tits. In both species, the intensity of competition was the strongest in poorquality habitats as reflected by food availability (Dhondt, 2010). A field experiment based on the exclusion of great tits from nest boxes during winter resulted in an increase in the abundance of blue tits (Dhondt \& Eyckerman, 1980b), demonstrating that competition for roosting sites in winter can limit population size of the smaller blue tit in some habitats. Such effects of competition in winter may have carryover effects on densities during the breeding season. In addition, observational monitoring of natural holes and experimental removal of access to tree cavities show that a shortage in nest sites can limit breeding population density in birds (Aitken \& Martin, 2008; Robles, Ciudad, \& Matthysen, 2011), even in cavity-rich environments (Robles, Ciudad, \& Matthysen, 2012), which in turn may lead to cascading effects via an increase in the intensity of interspecific competition (Aitken \& Martin, 2008).

Food availability is an underlying cause of limitation of population density in numerous organisms (Newton, 1998; Ruffino, Salo, 
Koivisto, Banks, \& Korpimäki, 2014). This has been shown clearly in food supplementation experiments: The addition of food often increases abundance, while food removal has the opposite effect (e.g. Dhondt, 2012; Dhondt, Kempenaers, \& Adriaensen, 1992; Minot, 1978, 1981; Siriwardena et al., 2007; Török \& Tóth, 1999). Likewise, extensive food provisioning in feeders by humans across broad spatial scales has caused dramatic increases in abundance of birds, and often also earlier timing of reproduction and increased reproductive success (review in Robb, McDonald, Chamberlain, \& Bearhop, 2008), especially in great tits (Tryjanowski et al., 2015). Another effect of urbanization is that laying date advances in urban plots because of food and/or higher temperatures in urban areas (e.g., Dhondt, Eyckerman, Moermans, \& Hublé, 1984; Wawrzyniak et al., 2015).

While interference competition mainly involves access to territories in spring and fall, and for cavities during the breeding season and in winter, exploitation competition is mainly over limiting food during the breeding season (Dhondt, 1977) and in winter (Krebs, 1971; Perdeck, Visser, \& Van Balen, 2000). If there is a change in timing or availability of food due to changing climate (Adler, HilleRisLambers, Kyriakidis, Guan, \& Levine, 2006; Angert, Huxman, Chesson, \& Venable, 2009; Parmesan \& Yohe, 2003; Stenseth et al., 2002; Visser, 2008; Visser \& Holleman, 2001; Visser, van Noordwijk, Tinbergen, \& Lessells, 1998), then both density-dependent and density-independent processes should affect tit populations (Dhondt \& Adriaensen, 1999; Stenseth et al., 2015; Wilkin, Garant, Gosler, \& Sheldon, 2006).

Intraspecific and interspecific competition among tits, but also other secondary hole-nesting taxa, and the resources subject to competition, are highly variable across spatial and temporal scales (Alatalo, 1984; Dhondt, 2012; Minot \& Perrins, 1986). Therefore, there is a clear need for addressing questions about competition at such scales. Both great and blue tits have a large distribution, and, therefore, they are ideal for addressing questions about competition at large spatial and temporal scales. The large temporal and spatial variation in the resources subject to competition is a source of variance that can readily be implemented into the study of competition, but has only been so to a very limited and, so far, unplanned extent (Stenseth et al., 2015). We suggest that deliberate comparison between sympatric populations of congeners inhabiting spatially and temporally variable environments will allow for much more powerful statistical tests.

The objective of this study was to assess the generality, at a large spatiotemporal scale, of effects of intraspecific and interspecific competition on laying date and clutch size of great and blue tits across Europe and Northern Africa using 35,800 clutches in nest boxes in areas where both species nest sympatrically. We predicted that (a) intraspecific competition, and to a lesser extent interspecific competition, would delay and increase the variance in laying dates and reduce clutch sizes. Furthermore, we predicted that (b) this effect should be more pronounced in blue than in great tits as interspecific competition increases given that blue tits are smaller than great tits. (c) At any one site, differences in density across time and hence differences in competition between great and blue tits would be related to differences in laying date and clutch size. If interspecific competition occurs, we predict a reduction in mean and an increase in variance in clutch size in great tit and blue tit when density of heterospecifics is higher than the density of conspecifics, and for intraspecific competition, this reduction would occur when density of conspecifics is higher than the density of heterospecifics. For laying date, we predicted for intraspecific competition a delay in mean laying date of great tits or blue tits when density of conspecifics outnumbered density of heterospecifics and the reverse for interspecific competition. A higher variance is a consequence of laying being delayed and clutch size reduced among individuals that suffer the most from competition with conspecifics or heterospecifics. This follows from the observation that at low density only highquality sites are occupied, while at high density poor-quality sites (where the birds lay smaller clutches) are also occupied resulting in increased variances at higher density (Dhondt et al., 1992; Ferrer \& Donázar, 1996; Solonen, Tiainen, Korpimäki, \& Saurola, 1991).

\section{MATERIALS AND METHODS}

\section{1 | Datasets}

We obtained information on density of occupied nest boxes per ha, nest box size, clutch size, laying date and ecological variables from all studies considered in this manuscript of two common species of secondary hole nesters, the great tit and the blue tit, across Europe and North Africa, as described in detail elsewhere (Møller et al., 2014a,b). Specifically, we obtained data on first clutches, or early clutches known to be initiated less than 30 days after the first egg was laid in a given year in a local study plot (cf. Nager \& van Noordwijk, 1995). In total, we obtained information on 87 study plots with both great and blue tits breeding during the period 1957-2012 (Møller et al., $2014 a, b)$. We chose study plots where both great and blue tits had been recorded breeding at least once in order to ensure that all study plots contained suitable habitats, breeding sites and nest boxes for both species. All data are available at DOI: https://doi.org/10.5061/ dryad.p763611.

\section{2 | Statistical analyses}

\subsection{1 | Linear mixed model of laying date and clutch size}

The study sites differed in a number of features that were controlled statistically as covariates or factors in the analyses because our previous studies have indicated that each of these variables is significant predictor of laying date and clutch size (Lambrechts et al., 2010; Møller et al., 2014a,b; Vaugoyeau et al., 2016). The variables were latitude $\left({ }^{\circ} \mathrm{N}\right)$ and longitude $\left({ }^{\circ} \mathrm{E}\right)$, main habitat type (deciduous, coniferous, evergreen or mixed), urbanization (urbanized, or natural/ seminatural habitat), altitude at the centre of the study plot, nest floor surface as the internal base area within the nest box (in $\mathrm{cm}^{2}$ ) 
and the material used to construct nest boxes (a binary variable classified as either wood or concrete). Further details of how these variables were obtained and quantified can be found in Lambrechts et al. (2010), Møller et al. (2014a,b) and Vaugoyeau et al. (2016).

We constructed eight linear mixed models (LMMs) with laying date and clutch size of great and blue tits as untransformed response variables and including all the above-mentioned confounding variables into the models. The density of great tit or blue tit was also included in the fixed part of the model, and its significance was tested by removing it from the saturated model testing for its effect using likelihood-ratio test (LRT). These eight models corresponded to laying date and clutch size of both species according to density of the species ( $=2$ variables $\times 2$ species $\times 2$ competition status (intraspecific/ interspecific competition). Density of great tits and blue tits in the study plots was estimated as the number of occupied nest boxes/ study area (ha) for each year and each species. The analyses of intraspecific and interspecific competition were restricted to those study plots where the duration of the study was at least 5 years, in order to be able to fit a random slope in the models of intraspecific competition. When testing for intraspecific competition (i.e., the effect of density of great tit in laying date and clutch size of great tit, or the effect of density of blue tit in laying date and clutch size of blue tit), we included study plot and year as two cross-random intercepts to account for differences among sites and years, but also we estimate the variance in the slope of the relationship between density and laying date or clutch size among study plots (e.g., the slope of density of great tit on laying date or clutch size of great tit among study plots). The significance of the random slope in these models was also tested using LRT, including only the intercept in the fixed part of the models (Crawley, 2002). The random slope was removed from the models when $p>0.05$. When testing for interspecific competition (i.e., the effect of density of great tit in laying date and clutch size of blue tit or the effect of density of great tit on laying date and clutch size of blue tit), study plot and year were included as two crossrandom intercepts to account for differences among sites and years. We did not include a random slope (e.g., the slope of the density of blue tit on laying date of great tit among study plots) because it might happen that in some study plots the number of observations could not match a model with and without the slope (e.g., when fitting a random slope for the density of blue tit on laying date of great tit, we had 921 observations for the model excluding the random slope and 920 observations in the model including a random slope). Therefore, it was possible that in one out of 5 or more years of study one of the two species of tit was not recorded. This occurred very infrequently (e.g., only in one plot out of 75 for the above example), but it did not allow us to test for the significance of a random slope when testing for interspecific competition.

All eight analyses were weighted by sample size to account for differences in sampling effort among study plots (Garamszegi \& Møller, 2010). We calculated variance inflation factors (VIF) to identify problems of collinearity. All VIFs were smaller than 5 , and in almost all cases smaller than 3 , indicating that there were no problems of collinearity (McClave \& Sincich, 2003). We standardized regression predictors by centring (i.e., subtracting the mean and dividing by $2 S D$ ). Therefore, numeric variables that take on more than two values were each rescaled to have a mean of 0 and a SD of 0.5 and binary variables were rescaled to have a mean of 0 and a difference of 1 between their two categories, while the factors with more than two categories remained unchanged (Gelman, 2008).

\subsection{2 | Tests for differences in laying date and clutch size}

We tested whether differences in clutch size between great and blue tits were related to differences in laying date between the two species and differences in density between great and blue tits, including their two-way interaction using standard least squares analyses, weighted by sample size. We included the interaction in order to test whether the difference in laying date had a stronger effect on difference in clutch size when the difference in density was larger. In addition, we tested whether differences in laying date were related to differences in density. In these analyses, we restricted the sample size to study plots with 5 or more years of study. Sample sizes differed slightly for different analyses due to missing values. Larger variances were the result of more heterogeneity in relationships between laying date or clutch size and density among study sites.

\subsubsection{Effects of difference in density on effects of competition on laying date and clutch size}

We used difference in log-transformed great tit density minus logtransformed blue tit density (henceforth density difference) as the predictor variable in the analyses to test for effects of competition on laying date and on clutch size (Table 3, Figure 3). By doing so, we controlled for any variable that would influence the breeding of the two tit species in a similar way at each site and year. When the density difference was negative, blue tits were more abundant than great tits. The relative strength of intraspecific compared to interspecific competition in blue tits will change from negative to positive density difference values (i.e., the relative strength of interspecific competition will increase), while the opposite is true for great tits.

\subsubsection{Effects of categorized density differences on laying date and clutch size}

We categorized density difference at three levels with similar number of data points: level 1: great tit density lower than blue tit density with log great tit density-log blue tit density being on average $-0.58, S E=0.02$, range -1.78 to -0.12 ; level 2 : great tit density similar to blue tit density with log great tit density-log blue tit density being on average 0.11 , $S E=0.01$, range -0.12 to 0.30 ; and level 3 : great tit density higher than blue tit density with log great tit density-log blue tit density being on average 0.66, $S E=0.02$, range 0.30-1.76. These data were used in a Welch ANOVA for unequal variances by comparing means between the three groups. We also compared variances among these three categories of density difference using Levene's test. 
TA B LE 1 Linear mixed models of laying date of great and blue tits in relation to density of great and blue tits after controlling statistically for latitude, latitude squared, longitude, longitude squared, longitude by latitude, main habitat type (fixed effect), urbanization (fixed effect), nest box material, altitude and nest floor surface as fixed effects, and year and study site as random factors. Only the partial effects of density are shown here after controlling statistically for the variables listed above. The analyses were weighted by sample size. Effect sizes were Pearson's product-moment correlation coefficients. The analyses were based on 921 observations from 87 plots for great tit and on 930 observations from 87 sites for blue tits. The majority of sites (more than 99\%) had at least 5 years of study or more

\begin{tabular}{|c|c|c|c|c|c|}
\hline Term & LRT & $p$ & Estimate & SE & Effect size \\
\hline Density of great tits & 6.13 & 0.01 & -1.458 & 0.597 & 0.29 \\
\hline Density of blue tits & 3.04 & 0.08 & 1.304 & 0.775 & 0.20 \\
\hline \multicolumn{6}{|l|}{ Blue tit laying date } \\
\hline Density of great tits & 4.34 & 0.04 & -1.051 & 0.511 & 0.24 \\
\hline
\end{tabular}

(a)

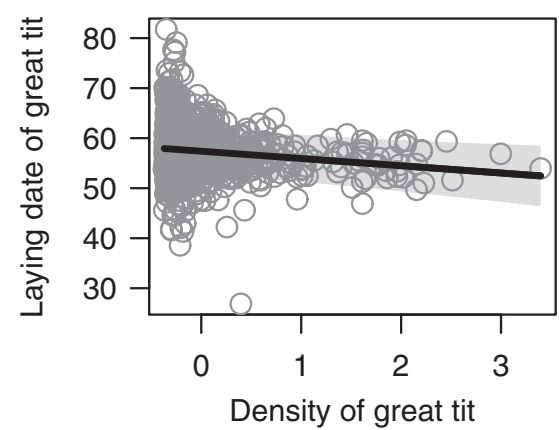

(c)

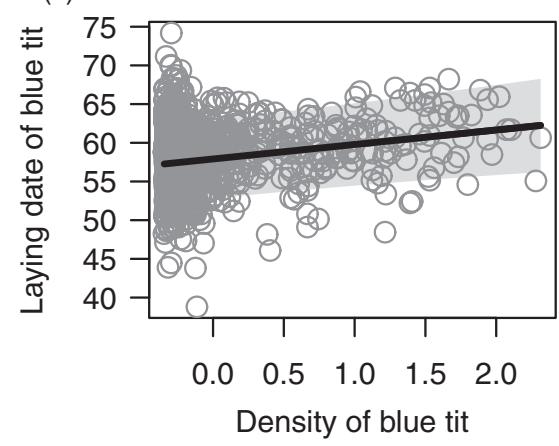

(b)

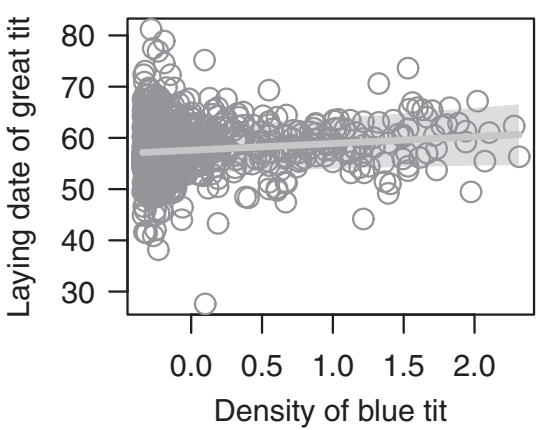

(d)

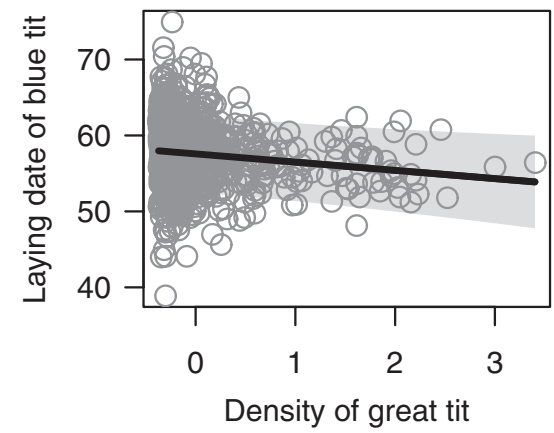

FIGURE 1 Laying date of great tit ( 1 = 1 March; $a, b)$ and blue tit (c, d) in relation to density of great tit (number of occupied nest boxes per ha; a, d) and blue tit (b, c). The lines are the predicted values with $95 \%$ confidence intervals obtained from the linear mixed-effect models while maintaining latitude, longitude and nest floor surface as their mean values. Main habitat type, urbanization and nest box material as their reference values (i.e., conifer, concrete and no urbanization, respectively). Black lines show significant trends and grey lines nonsignificant trends

\subsection{5 | Effects of spatial autocorrelation}

We included latitude, latitude squared, longitude, longitude squared and the interaction between latitude and longitude in all models to control statistically for spatial autocorrelation (Diniz-Filho, Rangel, \& Bini, 2008; Dorman et al., 2007; Legendre, 1993; Legendre \& Legendre, 2012; Lichtstein, Simons, Shriner, \& Franzreb, 2002). Analyses were made with JMP (SAS, 2012) and the library Ime4 (Bates \& Maechler, 2009) using R version 3.3.2 (R Core Team, 2016).

\section{3 | RESULTS}

\section{1 | Summary statistics}

The analyses of competition were based on a maximum of 978 plot by year estimates of laying date and clutch size varying due to differences in availability of data. We had data for a total of 87 plots where both species bred at least once. For great tits, mean laying date weighted by sample size was 23 April $(S E=0.36, N=929)$ and mean clutch size was 8.61 eggs ( $S E=0.04, N=970$ ). For blue tits, mean laying date was 24 April ( $S E=0.41, N=935)$ and mean clutch size was 9.93 eggs ( $S E=0.06, N=973$ ).

\subsection{Effects of intra- and interspecific competition on laying date and clutch size}

\subsection{1 | Laying date}

Across study plots, great tit laying date was on average earlier when density of great tits was higher (Figure 1a, Table 1). Laying date of great tits was marginally later at higher blue tit density (Figure 1b; $p=0.08$ ). This relationship was consistent among study plots as 
shown by the nonsignificant variance among study plots in the estimated slopes of the relationship between great tit density and great tit laying date for each study plot (variance explained $=13.71 \%$, LRT $=2.33, d f=2, p=0.31$ ). This is opposite to what is expected if intraspecific competition influences laying date and does not strongly support an effect of interspecific competition on great tit laying date.

Blue tit laying date was significantly later at higher conspecific density (Figure 1c, Table 1) supporting the hypothesis that intraspecific competition influences laying date. There was a large and statistically significant variance among study plots in the estimated slopes between blue tit density and blue tit laying date (variance explained $=25.20 \%, \mathrm{LRT}=78.79, d f=2, p<0.0001$ ) showing that the intensity of intraspecific competition varies strongly between study plots. Blue tit laying date was earlier when density of great tits was higher which is opposite to predictions if interspecific competition were to influence laying date (Figure $1 \mathrm{~d}$ ).

\subsection{2 | Clutch size}

Across study plots, great tit average clutch size did not vary significantly with conspecific density (Figure 2a; Table 2). This analysis yielded a large and statistically significant variance in the estimated slopes among study plots (variance explained $=27.78 \%, \mathrm{LRT}=24.85$, $d f=2, p<0.0001$ ) showing that the intensity of intraspecific competition varied strongly between study populations. We also found that great tit clutch size did not vary with blue tit density (Figure $2 b$ ).

Blue tit average clutch size decreased with increasing conspecific density (Figure 2c, Table 2) documenting an effect of intraspecific competition on clutch size across the range. Here, we also found that the variance in the estimated slopes among study plots was large and statistically significant (blue tit: variance explained $=26.08 \%$, $\mathrm{LRT}=38.63, d f=2, p<0.0001$; Table 2), indicating important differences in the intensity of intraspecific competition. Blue tit clutch size was independent of great tit density (Figure $2 \mathrm{~d}$ ) showing no effect of interspecific competition on blue tit clutch size.

\section{3 | Using differences in density to detect competition}

Mean laying date of blue and great tit was earlier at relative density level 2 (i.e., when great tit and blue tit numbers are similar) compared to levels 1 and 3. For great tit, variance in laying date was also the lowest at relative density level 2 , whereas for blue tit variance in laying date decreased progressively from relative density level 1 over level 2 to level 3 (Table 3). These results are consistent with both intraspecific and interspecific competition in great tit and for interspecific competition in blue tit.

Great tits laid their eggs later than blue tit (i.e., the difference in mean laying date between great tit and blue tit was positive) at relative density level 1 , and these differences decreased progressively to relative density level 2 and level 3 . Therefore, when great tits outnumbered blue tits (level 3 ) laying date of the two species became similar.

Mean clutch size of great tit and blue tit was the smallest at relative density level 1 (i.e., when blue tits outnumber great tits), while it was higher at relative density 2 and 3 (i.e., when either great tit or blue tit numbers are similar, or great tits outnumber blue tits). Likewise, variance in clutch size for both great tit and blue tit decreased from relative density level 1 to levels 2 and 3 (Table 3). For (a)

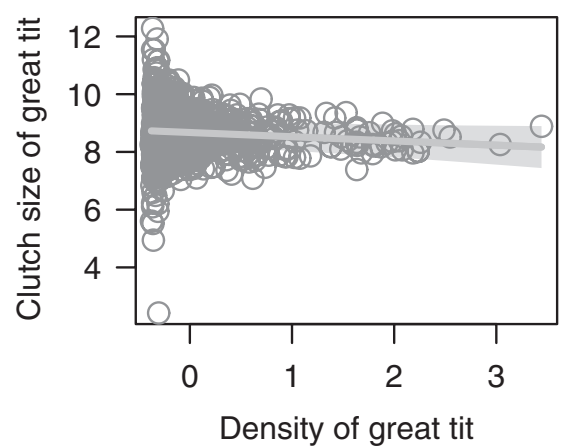

FIGURE 2 Clutch size of great tit (a, b) and blue tit (c, d) in relation to density of great tit (number of occupied nest boxes per ha; $a, c)$ and blue tit (b, d). The lines are the predicted values with $95 \%$ confidence intervals obtained from the linear mixed-effect models while maintaining latitude, longitude and nest floor surface as their mean values. Main habitat type, urbanization and nest box material as their reference values (i.e., conifer, concrete and no urbanization, respectively). Black lines show significant trends and grey lines nonsignificant trends (c)

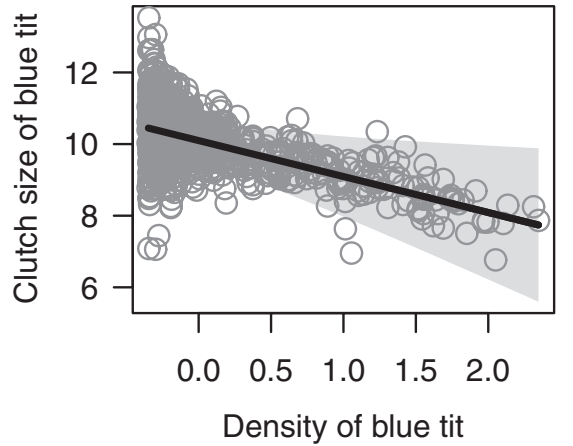

(b)

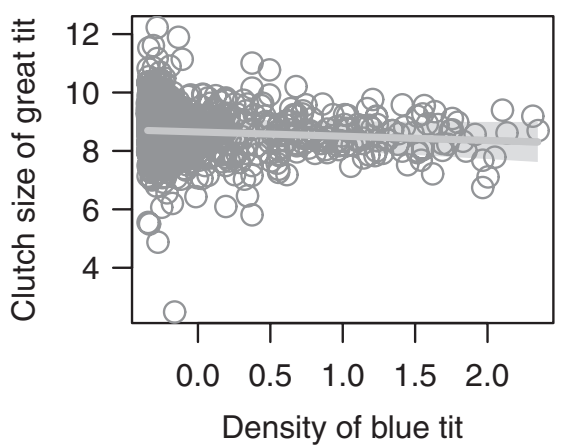

(d)

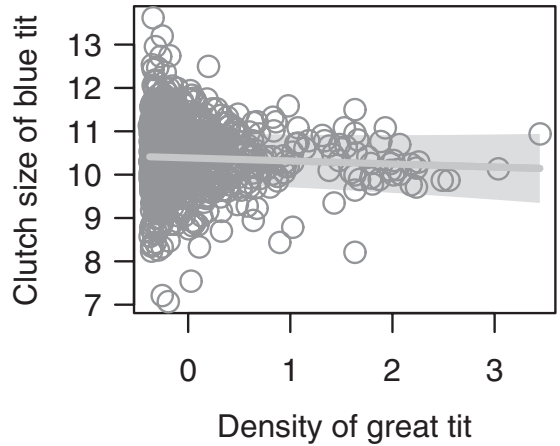


TAB LE 2 Linear mixed models of clutch size of great and blue tits in relation to density of great and blue tits after controlling statistically for latitude, latitude squared, longitude, longitude squared, longitude by latitude, main habitat type, urbanization, nest box material, altitude and nest floor surface as fixed terms, and study site and year as random factors. Only the partial effects of density are shown here after controlling statistically for the variables listed above. The analyses were weighted by sample size. Effect sizes were Pearson's productmoment correlation coefficients. The analyses were based on 966 observations from 87 sites for great tit and on 969 observations from 87 sites for blue tits. The majority of sites (more 99\%) had at least 5 years of study or more

\begin{tabular}{|lllll}
\hline Term & LRT & $p$ & Estimate & SE \\
\hline Great tit clutch size & & & & Effect size \\
\hline Density of great tits & 2.04 & 0.15 & -0.120 & 0.080 \\
\hline Density of blue tits & 2.36 & 0.12 & -0.157 & 0.102 \\
\hline Blue tit clutch size & & & & 0.17 \\
\hline Density of great tits & 0.78 & 0.38 & -0.073 & 0.079 \\
\hline Density of blue tits & 6.41 & 0.01 & -1.135 & 0.433 \\
\hline
\end{tabular}

great tits, these results are consistent with interspecific competition being more important than intraspecific competition, and for blue tits, the reverse occurred with intraspecific competition being more important than interspecific competition.

The difference in clutch size between great tit and blue tit tended to become more negative (i.e., blue tit clutch size greater than great tit clutch size) from relative density level 1 to level 3 . Therefore, when blue tits outnumbered great tits (level 1) the difference in clutch size between the two species was the smallest, and this difference became larger and favoured blue tits when great tits outnumbered blue tit (level 3). This is also consistent with intraspecific competition affecting blue tits (Table 3; Figure 3).

\section{DISCUSSION AND CONCLUSIONS}

This extensive study of spatial patterns in density dependence of laying date and clutch size in two species of secondary hole-nesting birds revealed several novel observations. This claim is implicit in the comparison of the three categories of differences in log density of great tit minus log density of blue tits. Here, we briefly discuss the broad conclusions that can be drawn from these results. The first novel observation was that intraspecific and interspecific competition are one and the same phenomenon in the two species of tits. However, the fact that we were working with two closely species using partly similar habitats and breeding sites may render this example of limited generality. The second novel observation was that the slope of conspecific density on laying date in blue tits (but not great tits) differed among study plots. The third novel observation was heterogeneity among study plots in slopes of conspecific density on clutch size of great and blue tits. The fourth novel observation was that changes in variance in laying date and clutch size provided tests for effects of density dependence impacting laying date and clutch size indirectly via the range of habitats occupied.

In the analyses of laying date and clutch size depending on conspecific and heterospecific density, we found evidence for an effect of intraspecific competition on blue tit laying date and blue tit clutch size. We did not find effects of intraspecific competition between great tit laying date and clutch size for great tits, nor effects of interspecific competition for either species. However, we did show differences between the two species, specifically that blue tits seemed to show stronger impacts of both intraspecific and interspecific competition, seemingly contradicting the second prediction. This difference among species may be due to differences in body size and hence differences in competitive ability in early spring when the smaller blue tit is at a selective advantage (Dhondt, 1977, 2010).

In order to further test our predictions, we also analysed patterns within study plots because such analyses are more powerful than within-plot analyses that automatically control for many potentially confounding variables showing the highest variation among plots. We investigated the relative impact of great and blue tit density on laying date and clutch size by testing the relation between the difference in density (density difference) of great and blue tits and laying date/clutch size. We started from the assumption that in coexisting species (and as found in previous work), intraspecific competition in tits is stronger than interspecific competition (Dhondt, 2012). We found the earliest laying date at density difference level 2 (great tit density similar to blue tit density) for both great and blue tit. Thus, laying date was later for both species when either the density of conspecifics or heterospecific increased, consistent with laying date being affected by intra- and interspecific competition in both species. The variance in laying date was also the lowest at density level 2 for great tit further suggesting intra- and interspecific competition for great tits, whereas the variance was the largest at density level 1 for blue tits consistent with intraspecific competition. Furthermore, given the previous results, we expected that if intraspecific competition generally occurred across our 87 study plots, blue tit clutch size should be the smallest at density difference level 1 , and the largest in level 2 (great tit density = blue tit density). Our results suggest that among blue tits intraspecific competition generally occurs, while interspecific competition may occur.

Laying date was the earliest at density level 2 for both great tit and blue tit. This latter result implies that, when analysing data across Europe and Northern Africa, controlling for differences in 

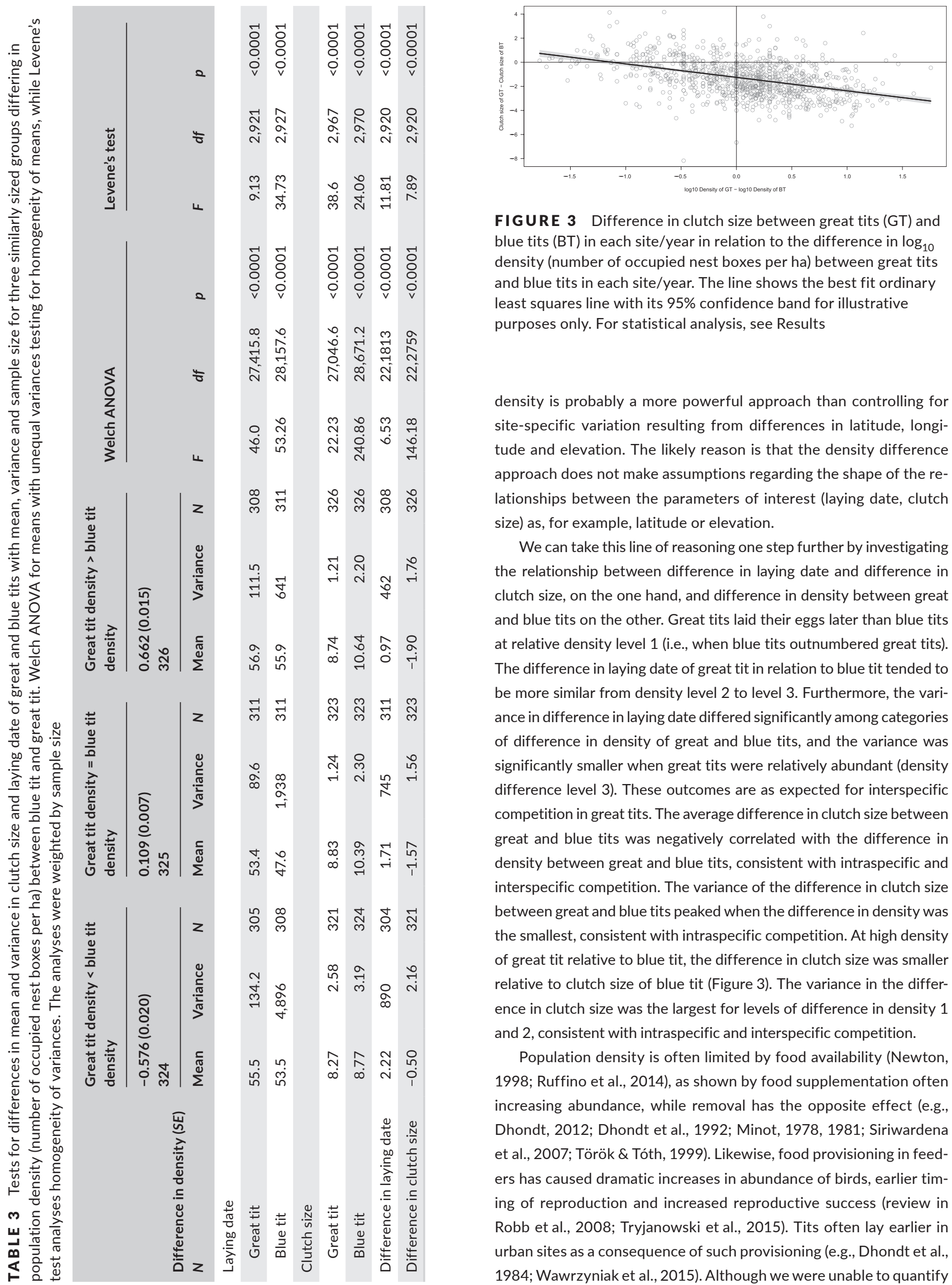

FIGURE 3 Difference in clutch size between great tits (GT) and blue tits (BT) in each site/year in relation to the difference in $\log _{10}$ density (number of occupied nest boxes per ha) between great tits and blue tits in each site/year. The line shows the best fit ordinary least squares line with its $95 \%$ confidence band for illustrative purposes only. For statistical analysis, see Results

density is probably a more powerful approach than controlling for site-specific variation resulting from differences in latitude, longitude and elevation. The likely reason is that the density difference approach does not make assumptions regarding the shape of the relationships between the parameters of interest (laying date, clutch size) as, for example, latitude or elevation.

We can take this line of reasoning one step further by investigating the relationship between difference in laying date and difference in clutch size, on the one hand, and difference in density between great and blue tits on the other. Great tits laid their eggs later than blue tits at relative density level 1 (i.e., when blue tits outnumbered great tits). The difference in laying date of great tit in relation to blue tit tended to be more similar from density level 2 to level 3. Furthermore, the variance in difference in laying date differed significantly among categories of difference in density of great and blue tits, and the variance was significantly smaller when great tits were relatively abundant (density difference level 3). These outcomes are as expected for interspecific competition in great tits. The average difference in clutch size between great and blue tits was negatively correlated with the difference in density between great and blue tits, consistent with intraspecific and interspecific competition. The variance of the difference in clutch size between great and blue tits peaked when the difference in density was the smallest, consistent with intraspecific competition. At high density of great tit relative to blue tit, the difference in clutch size was smaller relative to clutch size of blue tit (Figure 3 ). The variance in the difference in clutch size was the largest for levels of difference in density 1 and 2, consistent with intraspecific and interspecific competition.

Population density is often limited by food availability (Newton, 1998; Ruffino et al., 2014), as shown by food supplementation often increasing abundance, while removal has the opposite effect (e.g., Dhondt, 2012; Dhondt et al., 1992; Minot, 1978, 1981; Siriwardena et al., 2007; Török \& Tóth, 1999). Likewise, food provisioning in feeders has caused dramatic increases in abundance of birds, earlier timing of reproduction and increased reproductive success (review in Robb et al., 2008; Tryjanowski et al., 2015). Tits often lay earlier in urban sites as a consequence of such provisioning (e.g., Dhondt et al., 1984; Wawrzyniak et al., 2015). Although we were unable to quantify 
the effects of food on laying date and clutch size in this study, we assume that food limitation at least partially affects density.

Because means and variances are generally positively correlated (Wright, 1964), opposite results require a biological explanation. Here, we have shown that means and variances are positively correlated for difference in laying date between great tit and blue tit, while that is not the case for difference in clutch size. This requires an explanation. We hypothesize that the habitat heterogeneity hypothesis predicts an increase in the variance in reproductive parameters because at low density only high-quality sites are occupied, while at high density poor-quality sites (where birds lay a smaller and later clutch) are occupied (Dhondt et al., 1992; Ferrer \& Donázar, 1996; Krüger et al., 2012). We suggest that at high density poorquality sites are occupied, while in reality at high densities both highquality and poor-quality habitats are occupied, which would result in an increase in the variance in laying date and clutch size. Habitat heterogeneity is the mechanism that predicts that at higher density variance in clutch size should increase (Dhondt et al., 1992; Ferrer \& Donázar, 1996; Solonen et al., 1991). The analyses of effects of density are consistent with these predictions.

The present study was based on nest boxes, and the population density of the number of occupied boxes per unit area does not apply to the fraction of the population breeding in natural holes. This situation does not differ from analyses of other nest box populations (e.g., Dhondt, 2012; Dhondt et al., 1992; Gustafsson, 1987; Minot, 1978, 1981; Siriwardena et al., 2007; Stenseth et al., 2015; Török \& Tóth, 1999).

We analysed effects of competition in two congeneric secondary hole-nesting birds. It is likely that the hole-nesting community of birds and other animal taxa will have a similar or even stronger effect on the structure of the community of hole nesters. The present study predicts that similar analyses of laying date and clutch size in competing species such as other species of sympatric tits such as Poecile palustris and P. montanus and Ficedula flycatchers such as pied F. hypoleuca and collared flycatcher F. albicollis may allow quantification these effects of intra- and interspecific competition (Gustafsson, 1987). Analyses of such effects may be particularly powerful in a climate change scenario where the interacting parties are differently impacted by temperature and precipitation while the effects of study plot remain constant.

In conclusion, we have documented that within-plot analyses of laying date and clutch size in great and blue tits across 87 sites with known common breeding records distributed across Europe and North Africa provide a powerful tool for quantifying the effects of intraspecific and interspecific competition. We conclude that a similar approach may potentially be adopted in analyses of intraspecific and interspecific interactions among other taxa.

\section{ACKNOWLEDGEMENTS}

We would like to warmly thank the hundreds of collaborators and contributors who helped with study plot management, data collection, data management, administration, financial support and scientific discussion. Listing their names individually would most probably provide a biased picture of all of their contributions. T. Eeva acknowledges funding by the Academy of Finland (project 265859).

\section{AUTHORS' CONTRIBUTION}

A.P.M. conceived idea. A.P.M. and J.B. analysed data. A.P.M., J.B., A.A.D., F.A., C.B., J.C., M.C., B.D., A.D., M.E., T.E., A.E.G., A.G.G., L.G., P.H., S.A.H., S.J., R.J., T.L., B.L., B.M., T.D.M., R.G.N., J.-Å.N., S.G.N., A.C.N., R.P., V.R., H.R., T.S., A.S., A.J.v.N. and M.M.L. collected data. A.P.M., A.A.D. and J.B. wrote manuscript. A.P.M., J.B., A.A.D., F.A., C.B., J.C., M.C., B.D., A.D., M.E., T.E., A.E.G., A.G.G., L.G., P.H., S.A.H., S.J., R.J., T.L., B.L., B.M., T.D.M., R.G.N., J.-Å.N., S.G.N., A.C.N., R.P., V.R., H.R., T.S., A.S., A.J.v.N. and M.M.L. approved final manuscript.

\section{DATA ACCESSIBILITY}

Data available from the Dryad Digital Repository: https://doi. org/10.5061/dryad.p763611 (Møller et al., 2018).

\section{ORCID}

Anders Pape Møller (iD http://orcid.org/0000-0003-3739-4675

\section{REFERENCES}

Adler, P. B., HilleRisLambers, J., Kyriakidis, P. C., Guan, Q., \& Levine, J. M. (2006). Climate variability has a stabilizing effect on the coexistence of prairie grasses. Proceedings of the National Academy of Sciences of the United States of America, 103, 12793-12798. https:// doi.org/10.1073/pnas.0600599103

Aitken, K. E. H., \& Martin, K. (2008). Resource selection plasticity and community responses to experimental reduction of a critical resource. Ecology, 89, 971-980. https://doi.org/10.1890/07-0711.1

Alatalo, R. V. (1984). Evidence for interspecific competition among European tits Parus sp.: A review. Annales Zoologici Fennici, 19, 309-317.

Angert, A. L., Huxman, T. E., Chesson, P., \& Venable, D. L. (2009). Functional tradeoffs determine species coexistence via the storage effect. Proceedings of the National Academy of Sciences of the United States of America, 106, 11641-11645. https://doi.org/10.1073/ pnas.0904512106

Bates, D., \& Maechler, M. (2009). Ime4: Linear mixed-effects models using S4 classes. R package, version 0.999375-31. Retrieved from:http:// CRAN.R-project.org/package $=$ Ime 4

Both, C. (2000). Density dependence of avian clutch size in resident and migrant species: Is there a constraint on the predictability of competitor density? Journal of Avian Biology, 31, 412-417. https://doi. org/10.1034/j.1600-048X.2000.310317.x

Crawley, J. M. (2002). Statistical computing. An introduction to data analysis using S-Plus. Chichester, UK: Wiley.

Dhondt, A. A. (1977). Interspecific competition between great and blue tit. Nature, 268, 521-523. https://doi.org/10.1038/268521a0

Dhondt, A. A. (2010). Effects of competition on great and blue tit reproduction: Intensity and importance in relation to habitat quality. 
Journal of Animal Ecology, 79, 257-265. https://doi.org/10.1111/ j.1365-2656.2009.01624.x

Dhondt, A. A. (2012). Interspecific competition in birds. Oxford, UK: Oxford University Press.

Dhondt, A. A., \& Adriaensen, F. (1999). Experiments on competition between great and blue tit: Effects on blue tit reproductive success and population processes. Ostrich, 70, 39-48. https://doi.org/10.1080/0 0306525.1999 .9639748

Dhondt, A. A., \& Eyckerman, R. (1980a). Competition and the regulation of numbers in great and blue tit. Ardea, 68, 121-132.

Dhondt, A. A., \& Eyckerman, R. (1980b). Competition between the great tit and the blue tit outside the breeding season in field experiments. Ecology, 61, 1291-1296. https://doi.org/10.2307/1939036

Dhondt, A. A., Eyckerman, R., Moermans, R., \& Hublé, J. (1984). Habitat and laying date of great and blue tit Parus major and Parus caeruleus. Ibis, 126, 388-397.

Dhondt, A. A., Kempenaers, B., \& Adriaensen, F. (1992). Densitydependent clutch size caused by habitat heterogeneity. Journal of Applied Ecology, 61, 643-648. https://doi.org/10.2307/5619

Diniz-Filho, J. A. F., Rangel, T. F. L. V. B., \& Bini, L. M. (2008). Model selection and information theory in geographical ecology. Global Ecology and Biogeography, 17, 479-488. https://doi. org/10.1111/j.1466-8238.2008.00395.x

Dorman, C. F., McPherson, J. M., Araújo, M. B., Bivand, R., Bolliger, J., Carl, G., ... Wilson, R. (2007). Methods to account for spatial autocorrelation in the analysis of species distribution data: A review. Ecography, 30, 609-628. https://doi.org/10.1111/j.2007.0906-7590.05171.x

Ferrer, M., \& Donázar, J. A. (1996). Density-dependent fecundity by habitat heterogeneity in an increasing population of Spanish imperial eagles. Ecology, 77, 69-77. https://doi.org/10.2307/2265655

Garamszegi, L. Z., \& Møller, A. P. (2010). Effects of sample size and intraspecific variation in phylogenetic comparative studies: A metaanalytic review. Biological Reviews, 85, 797-805.

Gelman, A. (2008). Scaling regression inputs by dividing by two standard deviations. Statistics in Medicine, 27, 2865-2873. https://doi. org/10.1002/(ISSN)1097-0258

Grover, J. P. (1997). Resource competition. London, UK: Chapman \& Hall. https://doi.org/10.1007/978-1-4615-6397-6

Gurevitch, J., Morrow, L. L., Wallace, A., \& Walsh, J. S. (1992). A metaanalysis of competition in field experiments. The American Naturalist, 140, 539-572. https://doi.org/10.1086/285428

Gustafsson, L. (1987). Interspecific competition lowers fitness in collared flycatchers Ficedula albicollis: An experimental demonstration. Ecology, 68, 291-296. https://doi.org/10.2307/1939260

Houlahan, J. E., Currie, D. J., Cottenie, K., Cumming, G. S., Ernest, S. K. M., Findlay, C. S., ... Wondzell, S. M. (2007). Compensatory dynamics are rare in natural ecological communities. Proceedings of the National Academy of Sciences of the United States of America, 104, 3273-3277. https://doi.org/10.1073/pnas.0603798104

Keddy, P. A. (1989). Competition. London, UK: Chapman \& Hall. https:// doi.org/10.1007/978-94-010-9011-7

Krebs, J. R. (1971). Territory and breeding density in the great tit. Parus major L. Ecology, 52, 541.

Krüger, O., Chakarov, N., Nielsen, J. T., Looft, V., Grünkorn, T., StruweJuhl, B., \& Møller, A. P. (2012). Population regulation by habitat heterogeneity or individual adjustment? Journal of Animal Ecology, 81, 330-340. https://doi.org/10.1111/j.1365-2656.2011.01904.x

Lambrechts, M. M., Adriaensen, F., Ardia, D. R., Artemyev, A. V., Atiénzar, F., Bańbura, J., ... Ziane, N. (2010). The design of artificial nest boxes for the study of secondary hole-nesting birds: A review of methodological inconsistencies and potential biases. Acta Ornithologica, 45, 1-26. https://doi.org/10.3161/000164510X516047

Legendre, P. (1993). Spatial autocorrelation: Trouble or new paradigm? Ecology, 74, 1659-1673. https://doi.org/10.2307/1939924
Legendre, P., \& Legendre, L. (2012). Numerical ecology. New York, NY: Elsevier.

Lichtstein, J. W., Simons, T. R., Shriner, S. A., \& Franzreb, K. E. (2002). Spatial autocorrelation and autoregressive models in ecology. Ecology, 72, 445-463.

McClave, J. T., \& Sincich, T. (2003). Statistics (9th ed.). Englewood Cliffs, NJ: Prentice-Hall.

Minot, E. O. (1978). Interspecific competition in tits. Nature, 275, 463. https://doi.org/10.1038/275463b0

Minot, E. O. (1981). Effects of interspecific competition for food in blue tits (Parus caeruleus) and great tits (Parus major). Journal of Animal Ecology, 50, 125-137.

Minot, E. O., \& Perrins, C. M. (1986). Interspecific interference competition: Nest sites for blue and great tits. Journal of Animal Ecology, 55, 331-350. https://doi.org/10.2307/4712

Møller, A. P., Adriaensen, F., Artemyev, A., Bańbura, J., Barba, E., Biard, C., ... Lambrechts, M. M. (2014b). Variation in clutch size in relation to nest size in birds. Ecology and Evolution, 4, 3583-3595. https://doi. org/10.1002/ece3.1189

Møller, A. P., Adriaensen, F., Artemyev, A., Bańbura, J., Barba, E., Biard, C., ... Lambrechts, M. M. (2014a). Clutch size in European secondary hole-nesting passerines in relation to nest-box floor area, habitat, geographic location and study year. Methods in Ecology and Evolution, 5, 353-362. https://doi.org/10.1111/2041-210X.12160

Møller, A. P., Balbontín, J., Dhondt, A. A., Remeš, V., Adriaensen, F., Biard, C, ... Lambrechts, M. M. (2018). Data from: Effects of interspecific co-existence on laying date and clutch size in two closely related species of hole-nesting birds. Dryad Digital Repository, https://doi. org/10.5061/dryad.p763611

Nager, R. G., \& van Noordwijk, A. J. (1995). Proximate and ultimate aspects of phenotypic plasticity in timing of great tit breeding in a heterogeneous environment. The American Naturalist, 146, 454-474. https://doi.org/10.1086/285809

Newton, I. (1998). Population limitation in birds. Amsterdam, The Netherlands: Academic.

Parmesan, C., \& Yohe, G. (2003). A globally coherent fingerprint of climate change impacts across natural systems. Nature, 421, 37-42. https://doi.org/10.1038/nature01286

Perdeck, A. C., Visser, M. E., \& Van Balen, J. H. (2000). Great tit Parus major survival, and the beech-crop cycle. Ardea, 88, 99-108.

R Core Team. (2016). R: A language and environment for statistical computing. Vienna, Austria: R Foundation for Statistical Computing.

Ricklefs, R. E. (2012). Habitat-independent spatial structure in populations of some forest birds in eastern North America. Journal of Animal Ecology, 82, 145-154.

Robb, G. N., McDonald, R. A., Chamberlain, D. E., \& Bearhop, S. (2008). Food for thought: Supplementary feeding as a driver of ecological change in avian populations. Frontiers in Ecology and the Environment, 6, 476-484. https://doi.org/10.1890/060152

Robles, H., Ciudad, C., \& Matthysen, E. (2011). Tree-cavity occurrence, cavity occupation and reproductive performance of secondary cavity-nesting birds in oak forests: The role of traditional management practices. Forest Ecology and Management, 261, 1428-1435. https://doi.org/10.1016/j.foreco.2011.01.029

Robles, H., Ciudad, C., \& Matthysen, E. (2012). Responses to experimental reduction and increase of cavities by a secondary cavitynesting bird community in cavity-rich Pyrenean oak forests. Forest Ecology and Management, 277, 46-53. https://doi.org/10.1016/j. foreco.2012.04.017

Ruffino, L., Salo, P., Koivisto, E., Banks, B. P., \& Korpimäki, E. (2014). Reproductive responses of birds to experimental food supplementation: A meta-analysis. Frontiers in Zoology, 11, 80. https://doi. org/10.1186/s12983-014-0080-y

SAS. (2012) JMP version 10.0. Cary, NC: SAS Institute Inc. 
Schoener, T. W. (1983). Field experiments on interspecific competition. The American Naturalist, 122, 240-285. https://doi. org/10.1086/284133

Siriwardena, G. M., Stevens, D. K., Anderson, G. Q. A., Vickery, J. A., Calbrade, N. A., \& Dodd, S. (2007). The effect of supplementary winter seed food on breeding populations of farmland birds: Evidence from two large-scale experiments. Journal of Applied Ecology, 44, 920-932. https://doi.org/10.1111/j.1365-2664.2007.01339.x

Solonen, T., Tiainen, J., Korpimäki, E., \& Saurola, P. (1991). Dynamics of Finnish Starling Sturnus vulgaris populations in recent decades. Ornis Fennica, 68, 158-169.

Stenseth, N. C., Durant, J. M., Fowler, M. S., Matthysen, E., Adriaensen, F., Jonzén, N., ... Dhondt, A. A. (2015). Testing for effects of climate change on competitive relationships and coexistence between two bird species. Proceedings of the Royal Society of London B - Biological Sciences, 282, 20142929.

Stenseth, N. C., Mysterud, A., Ottersen, G., Hurrell, J. W., Chan, K. S., \& Lima, M. (2002). Ecological effects of climate fluctuations. Science, 297, 1292-1296. https://doi.org/10.1126/science.1071281

Török, J., \& Tóth, L. (1999). Asymmetric competition between two tit species: A reciprocal removal experiment. Journal of Animal Ecology, 68, 338-345. https://doi. org/10.1046/j.1365-2656.1999.00283.x

Tryjanowski, P., Morelli, F., Skórka, P., Goławski, A., Indykiewicz, P., Møller, A. P., \& Zduniak, P. (2015). Who started first? Bird species visiting novel birdfeeders. Scientific Reports, 5, 11858. https://doi. org/10.1038/srep11858

Vaugoyeau, M., Adriaensen, F., Artemyev, A., Bańbura, J., Barba, E., Biard, C., ... Møller, A. P. (2016). Interspecific variation in the relationship between clutch size, laying date and intensity of urbanisation in four species of hole-nesting birds. Ecology and Evolution, 6, 16.

Visser, M. E. (2008). Keeping up with a warming world: Assessing the rate of adaptation to climate change. Proceedings of the Royal Society of
London B - Biological Sciences, 275, 649-659. https://doi.org/10.1098/ rspb.2007.0997

Visser, M. E., \& Holleman, L. J. M. (2001). Warmer springs disrupt the synchrony of oak and winter moth phenology. Proceedings of the Royal Society of London B - Biological Sciences, 268, 289-294. https:// doi.org/10.1098/rspb.2000.1363

Visser, M. E., van Noordwijk, A. J., Tinbergen, J. M., \& Lessells, C. M. (1998). Warmer springs lead to mistimed reproduction in great tits (Parus major). Proceedings of the Royal Society of London B, 265, 18671870. https://doi.org/10.1098/rspb.1998.0514

Wawrzyniak, J., Kalinski, A., Gladalski, M., Banbura, M., Markowski, M., Skwarska, J., ...Banbura, J. (2015). Long-term variation in laying date and clutch size of the great tit Parus major in Central Poland: A comparison between urban parkland and deciduous forest. Ardeola, 62, 311-322.

Wilkin, T. A., Garant, D., Gosler, A. G., \& Sheldon, B. C. (2006). Density effects on life-history traits in a wild population of the great tit Parus major: Analysis of long-term data with GIS techniques. Journal of Animal Ecology, 75, 604-615. https://doi. org/10.1111/j.1365-2656.2006.01078.x

Wright, S. (1964). Evolution and the genetics of populations: Genetics and biometric foundations. Chicago, IL: University of Chicago Press.

How to cite this article: Møller AP, Balbontín J, Dhondt AA, et al. Effects of interspecific coexistence on laying date and clutch size in two closely related species of hole-nesting birds. J Anim Ecol. 2018;87:1738-1748. https://doi. org/10.1111/1365-2656.12896 